\title{
Matriks Pengontrol Pelepasan Urea Berbasis Karagenan: Pengaruh Konsentrasi Glutaraldehid
}

\author{
Sperisa Distantina *, Mujtahid Kaavessina, Fadilah
}

Program Studi Teknik Kimia, Fakultas Teknik, Universitas Sebelas Maret, J1. Ir. Sutami 36 A Surakarta 57126

*e-mail: sperisa_distantina@staff.uns.ac.id

\begin{abstract}
Abstrak. Pada penelitian ini, matrik hidrogel berbasis karagenan dibuat dan diaplikasikan untuk mengontrol pelepasan urea. Tujuan penelitian ini adalah mempelajari pengaruh konsentrasi glutaraldehid terhadap kecepatan pelepasan urea dan menyusun model kecepatan pelepasan urea. Film karagenan dimodifikasi secara kimiawi menggunakan ikatan silang atau crosslinking dengan glutaraldehid. Larutan karagenan $7 \mathrm{~g} / 100 \mathrm{~mL}$ dicetak menjadi lembaran dan kemudian dikeringkan sehingga diperoleh lapisan film. Film direndam dalam larutan glutaraldehid dengan konsentrasi tertentu selama 2 menit dan dilanjutkan dipanaskan pada suhu $110^{\circ} \mathrm{C}$ selama 20 menit. Film yang dihasilkan dicuci dengan etanol dan dikeringkan. Pengisian urea ke dalam matrik film menggunakan metode difusi. Film kering direndam dalam larutan urea $0,074 \mathrm{~g} / \mathrm{mL}$ selama satu jam dan selanjutnya dikeringkan. Kecepatan pelepasan urea dari film ke dalam media air dievaluasi berdasarkan data konsentrasi urea dalam cairan sebagai fungsi waktu. Berdasarkan hasil penelitian didapatkan bahwa semakin besar konsentrasi glutaraldehid (1$5 \%)$ menyebabkan urea yang tersimpan di dalam film semakin rendah. Model matematika yang diusulkan dapat mewakili peristiwa pelepasan urea dari film. Film berbasis karagenan yang dihasilkan berpotensi sebagai matrik pengontrol pelepasan urea.
\end{abstract}

Kata kunci: crosslinking, glutaraldehid, hidrogel, karagenan, urea.

Abstract. Controlled Release Matrices of Urea from Carrageenan: Effect of Glutaraldehyde Concentration. In this study, carrageenan-based hydrogel matrices were prepared and applied for urea controlled release. The aim of this work was to study the effect of glutaraldehyde concentration on the rate of urea release in water. Carrageenan films were chemically modified by crosslinking with glutaraldehyde. The films were prepared by casting the aqueous carrageenan $7 \mathrm{~g} / 100 \mathrm{~mL}$ and then followed by drying. The films obtained were immersed in certain glutaraldehyde concentration for $2 \mathrm{~min}$ and then heated in the oven at $110^{\circ} \mathrm{C}$ for $20 \mathrm{~min}$. The crosslinked films were washed using ethanol and then air-dried until the weight is constant. The dried films were immersed in a urea solution $(0.074 \mathrm{~g} / \mathrm{ml})$ for $1 \mathrm{hr}$ and then dried. The rate of urea release was determined by measuring the urea concentration in water as a function of time of release. Results showed that higher glutaraldehyde concentration (1-5\%) produced films with less urea content. The proposed mathematic model of urea release from the film can represent the rate of urea release. The prepared carrageenan-based film has the potential for controlling of urea release.

Keywords: carrageenan, crosslinking, glutaraldehyde, hydrogel, urea.

\section{Graphical Abstract}

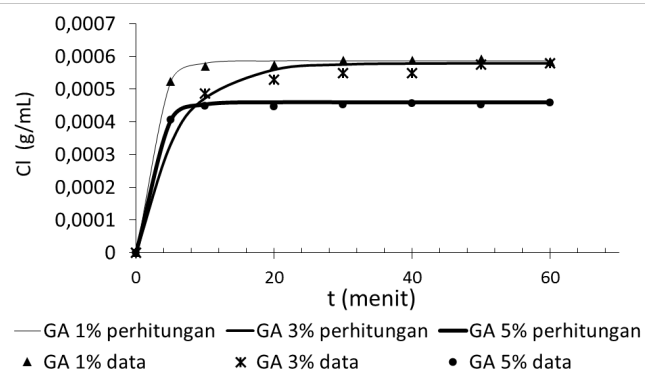

\section{Pendahuluan}

Efisiensi pupuk urea yang terserap tanaman hanya berkisar $30-50 \%$. Sisa pupuk yang tidak terserap akan larut terdegradasi dan terbawa aliran air. Rendahnya efisiensi penggunaan pupuk nitrogen, seperti urea, menyebabkan timbul beberapa efek negatif, seperti penurunan kesuburan tanah dan peningkatan polusi air tanah. Salah satu cara untuk mengatasi permasalahan itu adalah membuat matriks hidrogel berisi pupuk, sehingga pelepasan pupuk menjadi lebih lambat dan terkendali. Beberapa penelitian terdahulu mengkaji potensi polimer sebagai matriks pengontrol pelepasan pupuk, seperti karboksimetil selulosa (Ni dkk., 2011), poliasam akrilik (Tyliszczak dkk., 2009), kitosan (Lubkowski, 2014), dan poli(3-hidroksibutirat) (Akmal dkk., 2015). Matriks yang dikembangkan untuk 
pengendali pelepasan bahan aktif, seperti obat atau pupuk, merupakan matriks berstruktur polimer atau hydrogel (Djamaan dkk., 2015).

Hidrogel adalah matriks polimer yang memiliki struktuk ruang yang dapat mengikat air. Hidrogel adalah polimer jaringan tiga dimensi ikatan silang (crosslinked) hidrofilik yang mampu menyimpan air atau larutan fisiologis tetapi tidak mudah larut. Penelitian ini mengembangkan teknologi sintesis hidrogel pengontrol pelepasan urea berbasis polimer alam yang ramah lingkungan, yaitu karbohidrat yang tersedia melimpah di Indonesia. Penelitian ini memanfaatkan polimer alam lokal, yaitu karbohidrat karagenan yang dipungut dari rumput laut lokal Eucheuma cottonii. Metode crosslinking secara kimiawi, yaitu penggabungan dua atau lebih oleh ikatan kovalen, digunakan untuk memodifikasi polimer memiliki struktur hydrogel (Hoffman, 2002). Salah satu bahan crosslinker yang banyak digunakan adalah glutaraldehid. Glutaraldehid mampu mengikat gugus $\mathrm{OH}$ dalam polimer membentuk jaringan polimer yang rigid.

Untuk memprediksi kecepatan pelepasan urea dari matriks maka peristiwa transfer massa urea perlu dipelajari. Beberapa model matematika telah dikembangkan (Fernandez-Colino dkk., 2016). Namun, model yang dikembangkan tidak mempertimbangkan konsep keseimbangan antar fase (Treybal, 1980; Geankoplis, 1973). Tujuan penelitian ini mengembangkan model matematika yang dapat menggambarkan peristiwa pelepasan urea dari matriks ke dalam media berair dan mempelajari pengaruh konsentrasi glutaraldehid (GA) terhadap parameter dalam pelepasan urea. Film karagenan yang dimodifikasi dengan crosslinking menggunakan glutaraldehid digunakan sebagai matriks penyimpan urea.

Transfer massa antar fase digunakan untuk mendiskripsikan peristiwa pelepasan urea dari matrik hydrogel yang dihasilkan dalam penelitian ini. Transfer massa urea meliputi difusi urea dari fase padat (film hydrogel) ke badan utama air (cairan). Transfer massa berlangsung sampai mencapai keadaan jenuh atau seimbang. Keadadaan keseimbangan ditandai dengan tidak ada perubahan konsentrasi urea dalam pelarut terhadap waktu. Peristiwa transfer massa tersebut ditunjukkan oleh Gambar 1.

Kecepatan transfer massa urea dari permukaan film padatan ke fase cairan mengikuti persamaan (1).

$$
N A=k C a\left(C l^{*}-C l\right)
$$

Di batas antar fase, hubungan keseimbangan antara konsentrasi urea dalam cairan $(\mathrm{Cl} *)$ dan konsentrasi urea di permukaan padatan (Xs) mengukuti hukum Henry seperti yang ditunjukkan persamaan (2).

$$
C l^{*}=H . X S
$$

Konsentrasi urea dalam padatan setiap waktu ditentukan menggunakan neraca massa urea di cairan dan di padatan setiap saat, seperti ditunjukkan persamaan (3).

$$
X s=\frac{X o \cdot M+C l . V}{M}
$$

Hubungan konsentrasi urea dalam cairan sebagai fungsi waktu diturunkan dari evaluasi neraca massa urea dalam larutan setiap saat. Hubungan itu mengikuti persamaan (4).

$$
C l=\frac{b}{a}-\frac{b}{a} \exp (-a \cdot t)
$$

dengan,

$$
\begin{aligned}
& a=k C a . H .(V / M)+k C a \\
& b=k C a . H . X o
\end{aligned}
$$

\section{Metodologi}

\subsection{Bahan}

Bahan yang digunakan adalah tepung karagenan (ekstrak rumput laut Eucheuma cottonii) yang dibeli di toko lokal Surabaya, glutaraldehid (GA) 25\% dalam larutan air (Merck), etanol teknis yang dibeli dari toko lokal Surakarta, dan urea (Merck). Reagen ehrlich dibuat dengan cara 5 gr p-dimetilamino benzaldehid (Merck) dilarutkan dalam $20 \mathrm{ml}$ asam klorida pekat dan lalu diencerkan dengan air sampai $100 \mathrm{~mL}$.

\subsection{Pembuatan film karagenan}

Tepung karagenan dilarutkan dalam air menggunakan pemanasan $80^{\circ} \mathrm{C}$ dan pengadukan sehingga diperoleh larutan homogen $7 \mathrm{~g} / 100 \mathrm{ml}$. Larutan karagenan dicetak dan dikeringkan sehingga diperoleh film kering dengan berat konstan. Film yang diperoleh dipotong $1,5 \mathrm{~cm} \times 1,5 \mathrm{~cm}$ dan berat setiap potong film berkisar 0,03-0,04 gram.

\subsection{Crosslinking film karagenan}

Film karagenan direndam ke dalam larutan GA selama 2 menit. Variasi konsentrasi larutan GA adalah $1 \%$, 3\%, dan 5\%. Setelah ditiriskan, film dipanaskan dalam oven pada suhu $110^{\circ} \mathrm{C}$ selama 25 menit. Film yang dihasilkan dicuci menggunakan akuades dan direndam dalam etanol selama 4 jam. Selanjutnya film dikeringkan sampai berat konstan.

\subsection{Tahap pengisian urea ke dalam film karagenan \\ Proses mengisi urea ke dalam film menggunakan} metode perendaman, yaitu merendam film dalam larutan urea. Proses ini juga dilakukan untuk menentukan kadar urea yang terkandung dalam film mula-mula $(X o)$. Film dengan berat tertentu $(\mathrm{ml})$ direndam dalam larutan urea $0,074 \mathrm{gr} / \mathrm{ml}$ selama $1 \mathrm{jam}$. Film yang telah ditiriskan ditimbang dan dicatat beratnya $\left(m_{2}\right)$. Konsentrasi urea dalam film mula-mula dievaluasi menggunakan persamaan (7). 


$$
X o=\frac{\frac{m 2-m 1}{\rho a s} \cdot C a s}{m 1}
$$

\subsection{Tahap Pelepasan Urea dari Film Karagenan}

Kadar urea dalam air dianalisis dengan metode Ehrlich (Yatzidis dkk., 1964), yaitu larutan urea dilarutkan dalam reagen ehrlich dan kemudian ditentukan abosrbansinya menggunakan spektrofotometri (Genesys 20) UV VIS dengan panjang gelombang $420 \mathrm{~nm}$. Kurva standar hubungan absorbansi dengan konsentrasi larutan urea disusun untuk menentukan konsentrasi urea dalam larutan. Untuk menentukan kecepatan transfer massa urea dari film ke media air, film yang telah terisi urea direndam dalam air. Setiap interval waktu tertentu diambil cuplikan larutan sebanyak $4 \mathrm{~mL}$ untuk dianalisis konsentrasi urea menggunakan metode Ehrlich.

\subsection{Penentuan Konstanta Henry dan $\mathrm{kCa}$}

Kontanta Henry $(H)$ ditentukan berdasarkan konsentrasi urea dalam larutan saat kondisi keseimbangan tercapai. Nilai $\mathrm{Cl}$ maksimum sebagai fungsi waktu diambil sebagai $\mathrm{Cl}$ keseimbangan atau disebut sebagai $C l^{*}$. Nilai $X s$ dihitung menggunakan persamaan (3) and nilai $\mathrm{H}$ dievaluasi menggunakan persamaan (2). Nilai $k C a$ di persamaan (4) ditentukan dengan menebak nilai $\mathrm{kCa}$ yang memberikan nilai $\mathrm{Cl}$ perhitungan mendekati nilai $\mathrm{Cl}$ data. Optimasi nilai $\mathrm{kCa}$ ditentukan dengan minimasi sum of square error (SSE). Metode menebak dan minimasi SSE menggunakan program Solver dalam Excel. Persamaan SSE mengikuti persamaan (8).

$$
\operatorname{SSE}=\sum_{\mathrm{i}}^{\text {data }}(C l \text { data }-C l \text { perhitungan })^{2}
$$

Dengan $\mathrm{Cl}$ data adalah nilai $\mathrm{Cl}$ yang diperoleh dari data percobaan, sedangkan $\mathrm{Cl}$ perhitungan adalah nilai $\mathrm{Cl}$ yang dievaluasi menggunakan persamaan (4) dengan nilai $k C a$ tertentu.

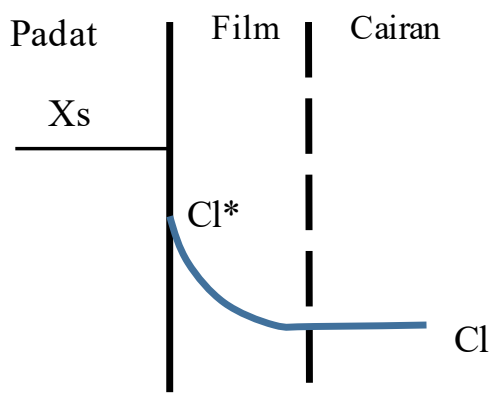

Gambar 1. Proses tansfer massa urea dari padatan ke fase air

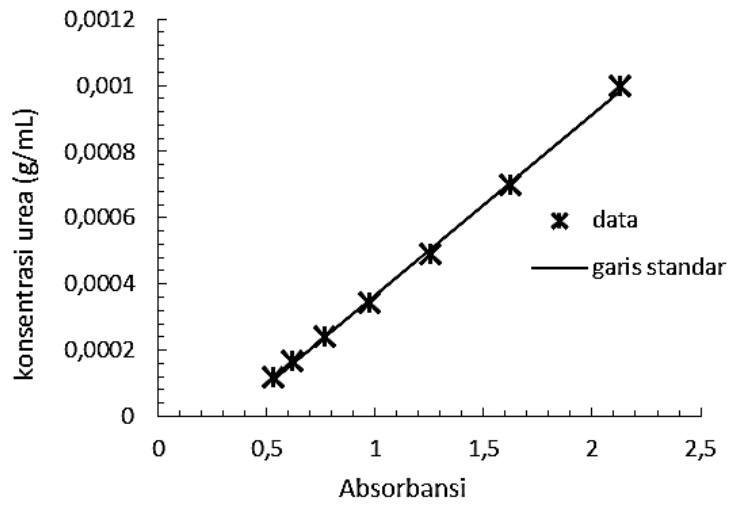

Gambar 2. Kurva standar hubungan konsentrasi urea dan absorbansi

\section{Hasil dan Pembahasan}

3.1. Kurva standard

Konsentrasi urea dalam air ditentukan dengan mengukur langsung aborbansi larutan dan dievaluasi berdasarkan kurva standar yang telah disusun (Gambar 2).

Berdasarkan metode regresi linier data konsentrasi urea $(C l)$ dan absorbansi $(A)$, diperoleh persamaan (9). Persamaan (9) digunakan untuk menentukan kadar urea dalam air berdasarkan data abosrbansinya.

$$
C l=0,0005 A-0,0002
$$

\subsection{Pengaruh konsentrasi GA terhadap $X o$}

Pada penelitian ini, film karagenan yang telah dimodifikasi strukturnya dengan crosslinking menggunakan glutaraldehid direndam dalam larutan urea $0,074 \mathrm{~g} / \mathrm{ml}$, agar film terisi urea. Tabel 1 menunjukkan hubungan konsentrasi GA sebagai bahan crosslinking dan banyaknya urea yang terdapat di dalam film. Banyaknya urea yang mengisi matriks film ditentukan berdasarkan banyaknya larutan urea yang mengisi film selama 60 menit. Tampak bahwa konsentrasi glutaraldehid sebagai bahan crosslinking sangat menentukan banyaknya urea yang dapat disimpan dalam film karagenan, seperti yang disajikan dalam Tabel 1.

Tabel 1. Pengaruh konsentrasi GA terhadap nilai Xo

\begin{tabular}{clll}
\hline \multirow{2}{*}{ Notasi } & \multicolumn{3}{c}{ Konsentrasi GA } \\
\cline { 2 - 4 } & GA 1\% & GA 3\% & GA 5\% \\
\hline$m_{1}(\mathrm{~g})$ & 0,5655 & 0,5264 & 0,8406 \\
$m_{2}-m_{1}(\mathrm{~g})$ & 2,2216 & 2,6876 & 1,6702 \\
$X o$ & 0,2907 & 0,3778 & 0,1470 \\
\hline
\end{tabular}


Tabel 2. Hubungan konsentrasi GA dengan parameter di tahap pelepasan urea dari film

\begin{tabular}{llll}
\hline \multirow{2}{*}{ Parameter } & \multicolumn{3}{c}{ Konsentrasi GA } \\
\cline { 2 - 4 } & GA 1\% & GA 3\% & GA 5\% \\
\hline$C l^{*}$ (saat $\mathrm{t}=1440$ menit) & 0,2907 & 0,3778 & 0,1470 \\
$X S$ (saat $\mathrm{t}=1440$ menit) & 0,1870 & 0,2678 & 0,0923 \\
$H$ & 0,0031 & 0,0022 & 0,0050 \\
$k C a$ & 0,2832 & 0,1202 & 0,2647 \\
\hline
\end{tabular}

Ada kecenderungan konsentrasi GA semakin tinggi maka nilai $X o$ semakin rendah. Hal ini menunjukkan bahwa banyaknya urea yang tersimpan berhubungan dengan jumlah jaringan ikat silang atau crosslinking. Konsentrasi GA semakin banyak menyebabkan ikat silang dalam polimer karagenan semakin banyak pula, dan akibatnya jaringan semakin rapat (Hoffman, 2002). Jaringan yang semakin rapat menyebabkan volum ruang yang dapat digunakan untuk menyimpan cairan semakin kecil. Kecenderungan ini juga dijumpai pada matriks karagenan yang diikat silang menggunakan $\mathrm{AlCl}_{3}$ (Lohani dkk., 2016).

Pada riset ini, crosslinking dengan GA $1 \%$ menghasilkan film yang mudah hancur. Berdasarkan pengamatan visual, fisik film yang dihasilkan dengan GA 1\% mulai hancur setelah 60 menit direndam dalam larutan urea $0,0074 \mathrm{~g} / \mathrm{ml}$, sementara film dengan GA $3 \%$ dan 5\% tidak hancur sampai 3 hari pengamatan direndam dalam larutan urea. Berdasarkan Tabel 1, tampak bahwa dengan GA 1\%, nilai Xo tidak lebih besar dari pada film dengan GA 3\%. Hal ini disebabkan pada saat perendaman sampai 60 menit, film dengan GA $1 \%$ mulai tidak dapat mempertahankan larutan urea yang mendifusi ke film. Seperti yang disebutkan di atas, dengan konsentrasi GA lebih besar menyebabkan jumlah ikat silang semakin banyak. Hal ini menyebabkan film yang menggunakan GA 3\% lebih kuat jaringannya dibandingkan film dengan GA 1\%. Dengan semakin banyak ikat silang maka ruang jaringan polimer yang dapat diisi cairan menjadi lebih sempit, seperti yang ditunjukkan dengan kadar urea yang dapat disimpan dalam film dengan GA 5\% lebih sedikit dibandingkan dengan GA 3\%.

\subsection{Pengaruh konsentrasi GA terhadap nilai $H$}

Nilai konstanta keseimbangan $H$ dievaluasi berdasarkan data film yang direndam dalam media air setelah 24 jam atau 1440 menit. Hasil perhitungan percobaan penentuan nilai $H$ disajikan dalam Tabel 2 .

Tabel 2 menunjukkan pengaruh konsentrasi GA terhadap nilai konsentrasi urea dalam larutan $\left(\mathrm{Cl}^{*}\right)$ yang berkeseimbangan dengan urea di dalam padatan saat kondisi sudah jenuh $(X s)$. Karena film dengan GA $1 \%$ hanya mampu menyimpan urea lebih sedikit dibandingkan film dengan GA 3\% (Tabel 1), maka hal ini menyebabkan banyaknya urea yang dapat dilepas dalam media air juga lebih sedikit.

Film dengan GA 3\% mampu menyimpan urea lebih banyak dibandingkan dengan film dengan GA 5\% (Tabel 1). Oleh karena itu, saat pelepasan urea dalam media air, film dengan GA 3\% menghasilkan konsentrasi urea dalam air lebih tinggi pada saat keseimbangan tercapai. Kerapatan jaringan ikat silang mendorong polimer mampu mengontrol pelepasan urea, seperti yang ditunjukkan nilai $X s$ (Tabel 2).

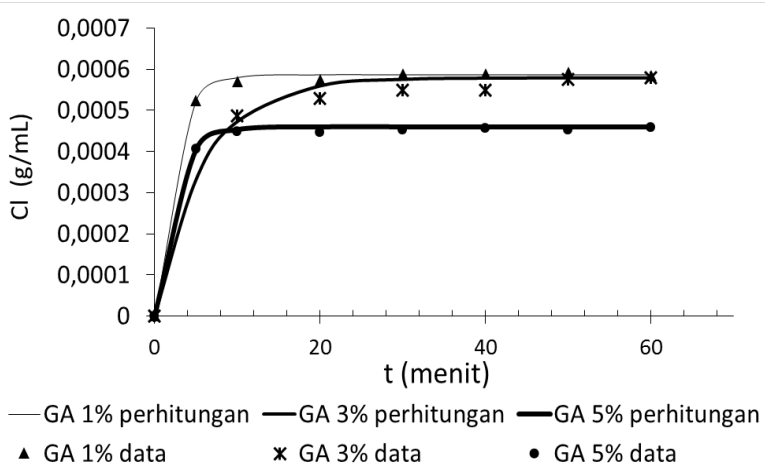

Gambar 3. Hubungan $C l$ sebagai fungsi waktu saat uji pelepasan urea dari film

\subsection{Pengaruh konsentrasi GA terhadap nilai $\mathrm{kCa}$}

Data percobaan konsentrasi urea dalam air $(\mathrm{Cl})$ sebagai fungsi waktu difusi urea dari film ke dalam media air disajikan dalam Gambar 3, sedangkan hasil perhitungan $\mathrm{kCa}$ disajikan dalam Tabel 2. Tampak bahwa, konsentrasi urea dalam air mulai jenuh dicapai setelah sekitar 10 menit film direndam dalam air. Pada penelitian ini, peristiwa transfer massa urea terjadi sangat cepat kurang dari 10 menit. Nilai $X s$ pada Tabel 1 menunjukkan jumlah urea yang terdapat dalam film saat kondisi jenuh ini tercapai. Data ini menunjukkan bahwa film berbasis karagenan ini mampu menahan pelapasan urea, sehingga film ini memiliki potensi sebagai pengatur pelepasan urea.

Gambar 3 juga menunjukkan pembandingan nilai konsentrasi urea data percobaan dan nilai konsentrasi urea hasil perhitungan berdasarkan model matematika yang diusulkan dengan nilai $\mathrm{kCa}$ tertentu. Nilai $\mathrm{Cl}$ hasil perhitungan ( $\mathrm{Cl}$ perhitungan) mendekati nilai $\mathrm{Cl}$ data, hal ini menunjukkan bahwa model matematika yang diusulkan dapat menggambarkan peritiwa transfer massa urea dari film ke dalam air.

\section{Kesimpulan}

Berdasarkan data percobaan, tampak bahwa film berbasis karagenan dengan konsentrasi GA 1\% sebagai bahan crosslinking tidak mampu mempertahankan kestabilan jaringan di media berair, sedangkan konsentrasi GA 3\% dan 5\% berpotensi sebagai matriks pengendali pelepasan urea dalam media berair. Model matematika yang diusulkan dapat mewakili peristiwa pelepasan urea dari film ke media berair.

\section{Daftar Notasi}

$\begin{array}{ll}\text { Cas } & \text { konsentrasi larutan urea }(\mathrm{g} \text { urea/ } \mathrm{mL}) \\ \mathrm{Cl} & \text { konsentrasi urea di cairan }(\mathrm{g} \text { urea } / \mathrm{mL})\end{array}$ 


\begin{tabular}{|c|c|}
\hline$C l^{*}$ & $\begin{array}{l}\text { konsentrasi urea di cairan yang } \\
\text { berkeseimbangan dengan konsentrasi urea } \\
\text { di permukaan padatan }(\mathrm{g} \text { urea } / \mathrm{mL})\end{array}$ \\
\hline$H$ & konstanta Henry (g padatan/mL larutan) \\
\hline$k C a$ & $\begin{array}{l}\text { koefisien transfer massa volumetris } \\
(1 / \text { menit })\end{array}$ \\
\hline$M$ & massa padatan film $(\mathrm{g})$ \\
\hline$m_{1}$ & berat film sebelum direndam $(\mathrm{g})$ \\
\hline$m_{2}$ & berat film setelah direndam $(\mathrm{g})$ \\
\hline$t$ & waktu (menit) \\
\hline$V$ & volume larutan (ml) \\
\hline Xo & urea dalam film (g urea / g film) \\
\hline$X S$ & $\begin{array}{l}\text { kadar urea dalam padatan setelah direndam } \\
\text { dalam air selama } t \text { tertentu ( } g \text { urea/g } \\
\text { padatan) }\end{array}$ \\
\hline$\rho a$ & densitas larutan urea $(\mathrm{g} / \mathrm{mL})$ \\
\hline
\end{tabular}

\section{Ucapan Terima Kasih}

Tim penulis menyampaikan terima kasih kepada Kementerian Riset, Teknologi, dan Pendidikan Tinggi Indonesia yang telah mendanai kegiatan riset ini melalui Hibah Fundamental PNBP Universitas Sebelas Maret 2017-2018.

\section{Daftar Pustaka}

Djamaan, A.; Monica, R.; Asiska, P.D.; Suardi, M.; Ben, E. S.; Erizal, Z., The Use of Biopolymer of Poly(3-hydroxybutyrate) as Matrix of Urea Slow Release Fertilizer. Journal of Chemical and Pharmaceutical Research, 2015, 7(7), 558-563.

Fernández-Colino, A.; Bermudez, J.M.; Arias, F.J.; Quinteros, D.; Gonzo, E., Development of A Mechanism and An Accurate and Simple Mathematical Model for The Description of Drug Release: Application to A Relevant Example of AcetazolamideControlled Release from A Bio-inspired Elastin-based
Hydrogel. Materials Science and Engineering C, 2016, 61, 286-292.

Geankoplis, C.J., Transport Processes and Unit Operations, $3^{\text {th }}$ ed. Singapore: McGraw-Hill Book Co., 1973.

Hoffman, A.S., Hydrogel for Biomedical Applications. Advanced Drug Delivery Reviews, 2002, 43, 3-12.

Lohani, A.; Singh, G.; Bhattacharya, S.S.; Hegde, R.R.; Verma, A., Tailored-interpenetrating Polymer network Beads of k-carrageenan and Sodium Carboxymethyl Cellulose for Controlled Drug Delivery. Journal of Drug Delivery and Technology, 2016, 31, 53-64.

Lubkowski, K., Coating Fertilizer Granules with Biodegrabable Materials for Controlled Fertilizer Release. Environmental Engineering and Management Journal, 2014, 13(10), 2573-2581.

Ni, B.; Liu, M.; Lu, S.; Xie, L.; Wang, Y., Environmentally Friendly Slow Release Nitrogen Fertilizer, Journal of Agricultural and Food Chemistry, 2011, 59(18), 10169-10175.

Treybal, R.E., Mass Transfer Operations, 3th ed. Singapore: McGraw-Hill Book Company, 1980.

Tyliszczak, B.; Polaczek, J.; Pielichowski, K., PAAbased Hybrid Organic-inorganic Fertilizer with Controlled Release. Polish Journal of Environmental Studies, 2009, 18(3), 475-479.

Yatzidis, H.; Garidi, M.; Vassilikos, C.; Mayopoulou, D.; Akilas, A., An Improved Method for the Simple and Accurate Colorimetric Determination of Urea with Ehrlich's Reagent'. Journal of Clinical Pathology, 1964, 17(2), 163-164. 